\title{
Laser Positioning System Using RFID-tags
}

\author{
Shintaro Sakamoto $^{{ }^{1}}{ }$, Naruo Kano ${ }^{2}$, Takeshi Igarashi ${ }^{2}$, and Hiroyuki Tomita ${ }^{1}$ \\ ${ }^{1} R \& D$ Center, Shinryo Corporation, Tsukuba, Japan \\ ${ }^{2}$ Department of Architecture Engineering, Waseda University, Tokyo, Japan \\ *Corresponding author (sakamoto.sh@shinryo.com)
}

\begin{abstract}
Purpose We developed a production system for performing renovation work with increased use of pre-cut and prefabrication elements. To develop this system, a faithful 3D-CAD model of an existing building was made using a 3D-laser scanner. The purpose of this research is to develop a method for positioning the pre-cut and pre-fabrication elements precisely and at short notice. Method First, a 3D-CAD model for renovation was made using the point cloud data of an existing building measured by a 3D-laser scanner. Next, the ID-number and the attribute data of the elements of the 3DCAD model were stored in a database. The database was then sent to the factory along with the fabrication design drawings. The RFID-tags were put on the corresponding elements in the factory. This system automatically identified the delivered elements by reading the RFID-tags, highlighting the appropriate elements of the 3D-CAD models, and it extracting the positions coordinates automatically. The coordinate data were sent to the automatic positioning system using the motor-driven total station developed by us; the workers were shown the positions by employing laser radiation. The coordinates of the positions were defined on each element and registered as individual information of the element objects. Thus, it is possible to obtain the position information of the elements by simply locating the element objects on the 3D-CAD. Results \& Discussion In our experiment we installed a dry wall in a room in an existing building. Our system helped in eliminating the marking process, and the wall could be installed using only pre-cut elements. However, some issues that need to be tackled in the future were revealed: (i) it might be impossible to point the laser to the position for an element if this position is in mid-air; (ii) since assembling is performed in a particular sequential manner, a method for searching and identifying a required element is needed.
\end{abstract}

Keywords: automation, renovation work, total station, 3D CAD, RFID tag, positioning

\section{INTRODUCTION}

On a construction site, the members and equipment are positioned based on manual marking performed using convex, plumb, and laser instruments after referring to the drawings. However, it is difficult to improve the working efficiency and accuracy because of the need for this manual work. In addition, there is a possibility of human errors because of the requirement of reading the drawing on site. In contrast, various information technologies such as the total station, 3D-CAD and GPS have been developed in civil engineering work ${ }^{1,2}$. The authors have developed a system that extracts the positioning data of members from 3D-CAD and positions them simply and accurately using the automatic laser pointing function of a motor-driven total station ${ }^{3}$

In this report, we provide a detailed description of the laser positioning system using an RFID tag and suggest future topics for this research by performing two experiments. These involve the installation of a partition wall in a room and piping work in an airconditioning machine room.

\section{CONFIGURATION AND FLOW OF SYSTEM}

The system configuration is shown in Figure 1. The $\mathrm{C}$ ontrol system of the total station (TS Controller), 3D CAD viewer, and positioning system using an RFID t ag (RFID Positioning System) are installed in a lapto p computer. The laptop can communicate with the tot al station and RFID reader through a wireless LAN a nd Bluetooth.

The flow of this system is shown in Figure 2. First, a database of the members is assembled from the $3 D$ CAD model and sent with the drawings to the factori es. Next, the members are fabricated and equipped with RFID tags. Their ID numbers are recorded in the database. The members are brought to the construct ion site and identified by an RFID reader, and the po sition data are extracted from the 3D CAD model. Fin ally, the total station points out the position using a la ser.

\section{DEFINING POSITIONING POINTS}

In this system, the member objects are previously re gistered in the library, allowing the operator to create a design by locating the objects in 3D-CAD. Defining the positioning points to each object enables to give $t$ he coordinate data of the position by locating them.

We previously proposed a method to create the mark ing data by locating the specific objects referring to $t$ he drawings. The method proposed in this paper ma kes it possible to save the work for making the data a nd prevents human errors.

As examples of positioning points, those for the mem bers of a drywall partition, pipes, and ducts are show $\mathrm{n}$ below. 


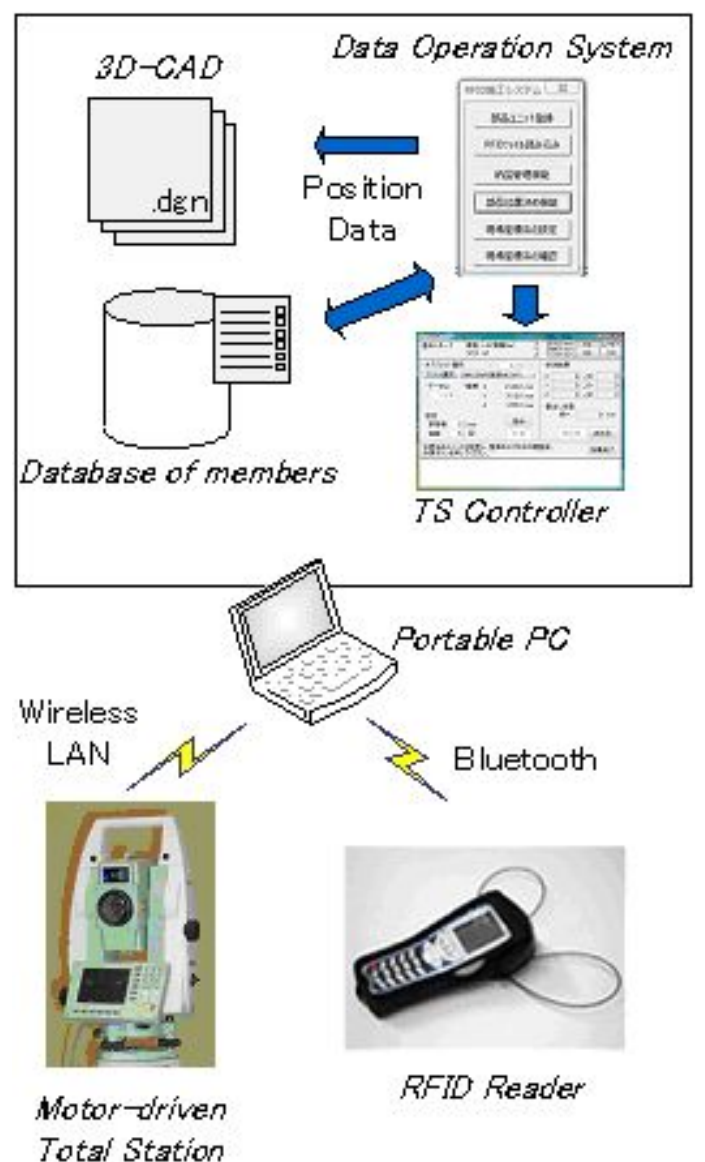

Fig.1 System Configuration

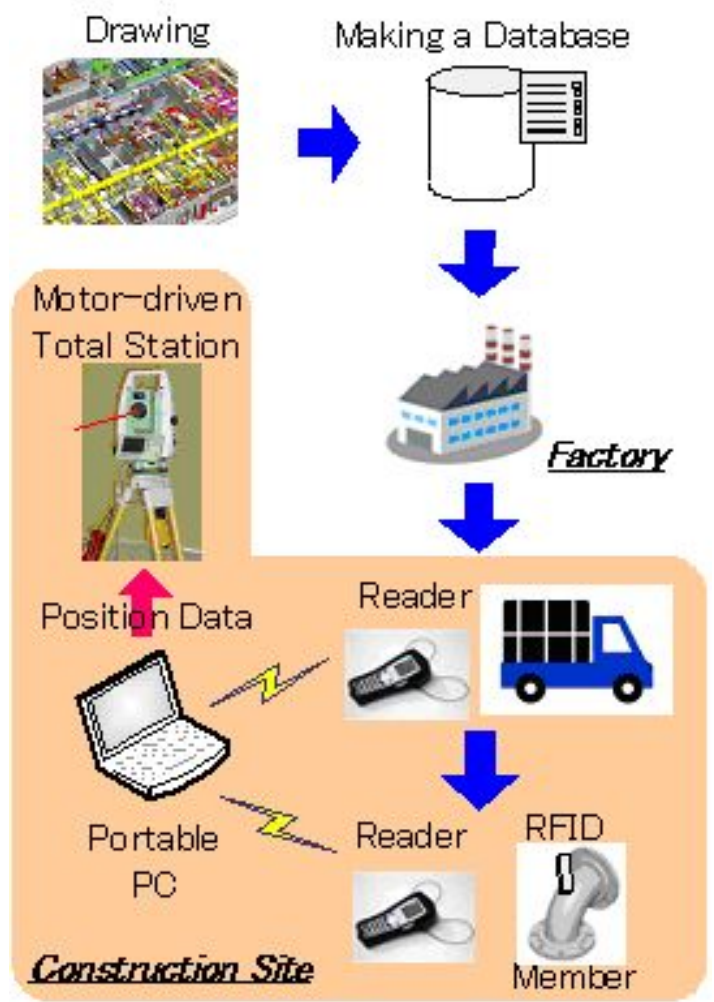

Fig.2 System Flow
(1) Runner

The positioning points of a runner are on the surface of the frames because it is fixed directly to them. The refore, the positioning points are defined as the cent er points of both edges considering the positioning a ctivity.

(2) Stud

As shown in Figure 3(b), the positioning points of stu ds are defined as the points beside the runner on the floor because they are fixed on the runner at even in tervals. The lines are scratched at the stud positions in the factory. The initial $D$ in this figure is the setting value, which was $20 \mathrm{~mm}$ in the experiment shown be low.

(3) Plasterboard

Plasterboard is set on the runner and studs, and gen erally the joint falls on the centerline of a stud. Theref ore, the positioning points are defined as the corners at the bottom of the board, as shown in Figure 3(c).

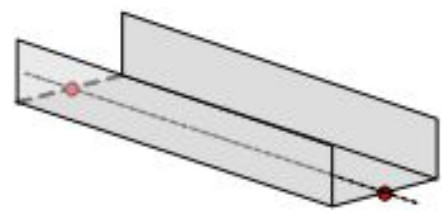

(a) Runner

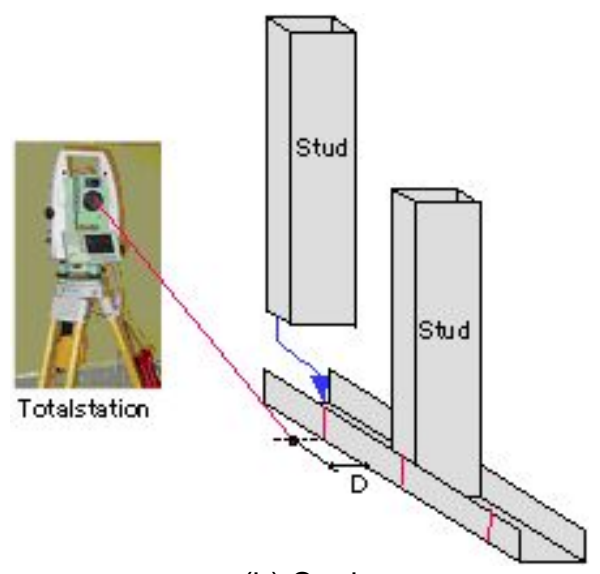

(b) Stud

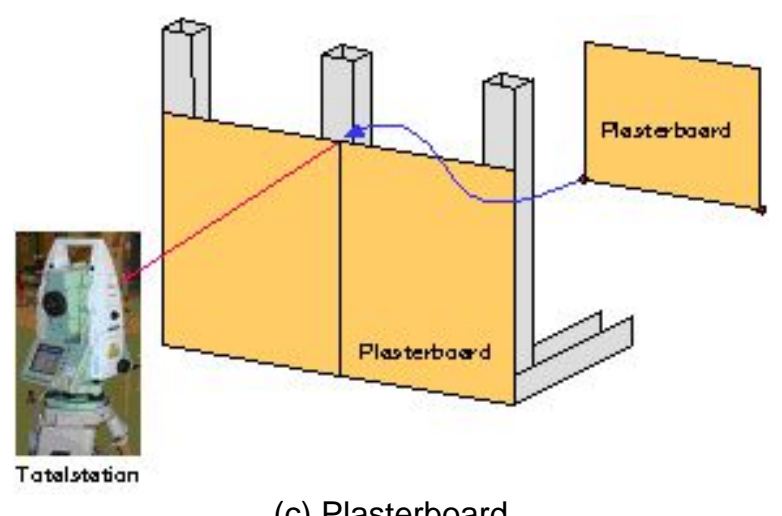

(c) Plasterboard

Fig.3 Positioning Points of Drywall Partition Members 


\section{(4) Pipe and Duct}

Members of the equipment are also divided into two categories: the members set directly on the frames a nd those set using supports. The positioning points $f$ or the former are anchor bolts in most cases. On the other hand, the latter cannot be indicated using the I aser because their positions are in the air. Therefore, the positioning points are defined as the positions of the supports fixed on the frames, which are the posit ions of the anchor bolts, as shown in Figure 4. This $s$ ystem would detect all of the supports attached to a pipe or duct in CAD, and extract the coordinates of $t$ he positioning points automatically.

\section{COOPERATION BETWEEN RFID TAG AND CAD Database of members}

First, a database of the members is created. The me mbers organized as a "Group" or "Module" are select ed in CAD. Group indicates a unit that is to be broug ht to the site, while Module indicates a combination o $f$ members that will be assembled in a factory. An ex ample of organizing a pipe module is shown in Figur e 5.

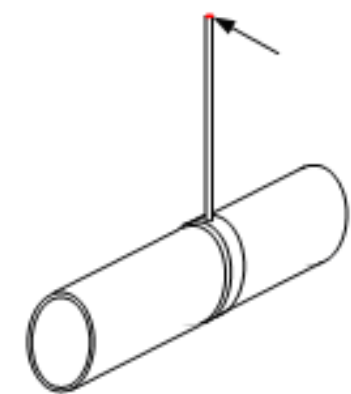

(a) Case of Pipe

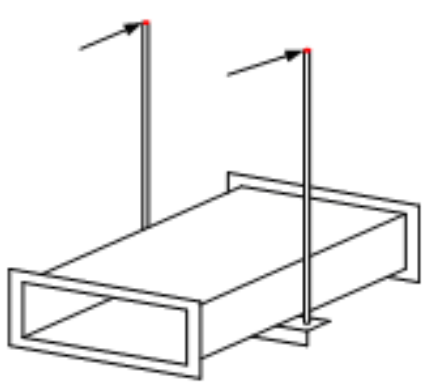

(b) Case of Duct

Fig.4. Positioning Points of Pipe and Duct

The items of data include the ID number of the RFID tag, file name, group or module name, type, name, sizes, and order and delivery dates. The database is output in the CSV format and sent to the factory with the CAD data.

\section{Management of delivery of members}

RFID tags are placed on the members manufactured in the factory, and the ID numbers are recorded in the database of members. The database is sent to the site and loaded into the system. The system verifies that all of the members of the groups are brought to the site by reading the tags and records the delivery date in the database. At the same time, it indicates the area of the group by highlighting it in CAD.

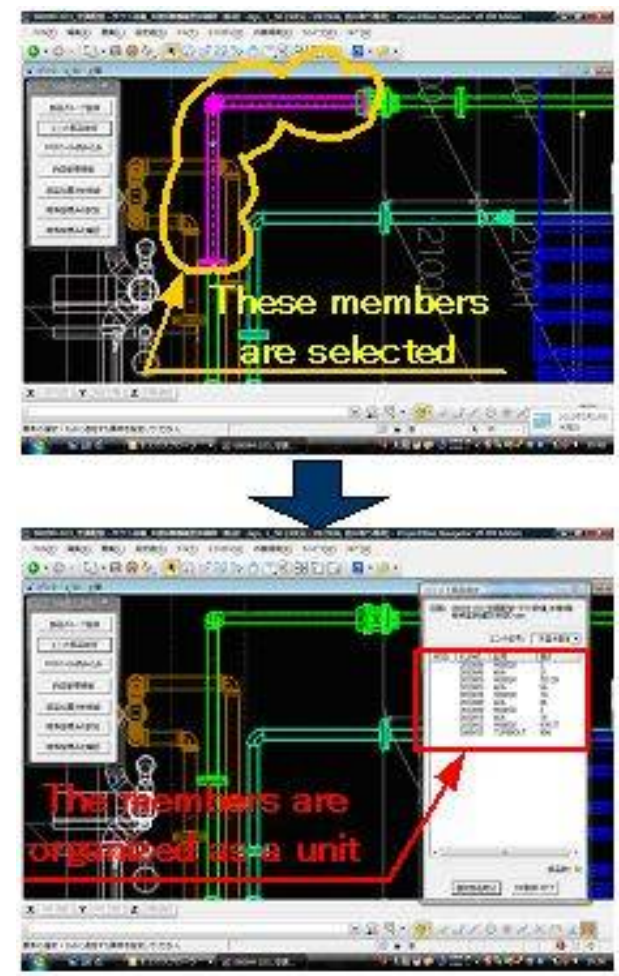

Fig.5. Example of Pipe Unit Registration

\section{Extracting positioning data for members}

When a tag of an arbitrary member is read, the system recognizes it, along with all of the members of the same type and size, and shows the list. The operator is able to select one using one of three methods.

(1) Select manually

All of the relevant members are shown by highlighting. The operator then selects one manually.

(2) Select by designated direction

The system selects the member according to the designated direction and shows it by highlighting automatically.

(3) Select by free

The system selects the member nearest to the previous one and shows it by highlighting automatically.

\section{Positioning with total station}

The total station is an instrument that can calculate the 3D coordinates of a laser point by measuring the horizontal angle, vertical angle and distance. Using a motor-driven total station makes it possible to indicate any point using an inverse calculation. The coordinates of the positioning points of the selected members are in the form of CSV data. When the operator opens the data file and operates the pointer 
through the TS controller, the total station points to the position with the laser automatically. Here, in a case where the position of the surface radiated with the laser is different from the drawing, the position of the laser pointer is different from the target. Therefore, this system has a function to correct the position by measuring the coordinates of the laser point.

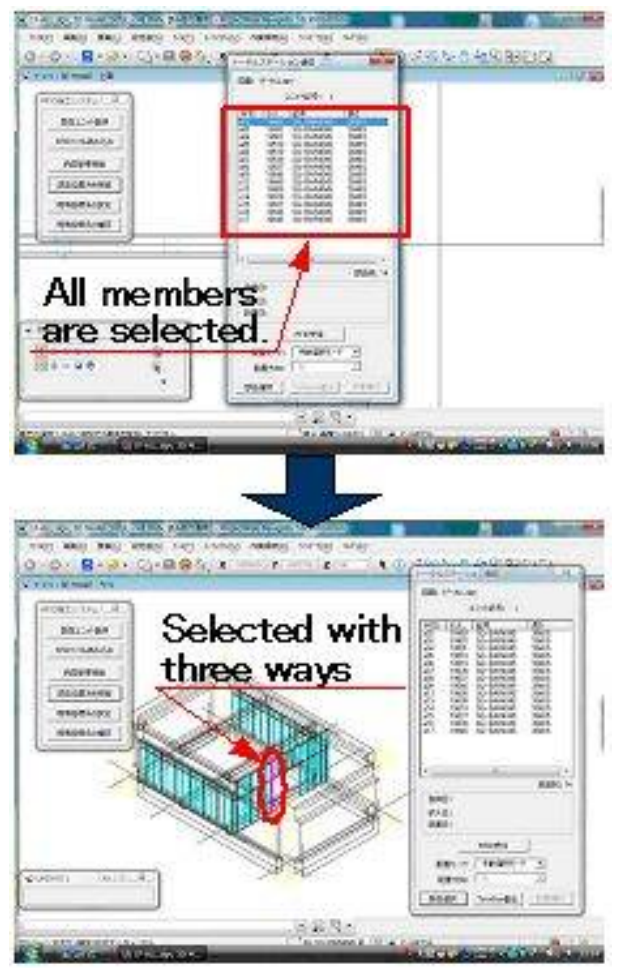

Fig.6. Selecting Member

\section{FIELD TEST}

\section{Applied to installation of partition wall}

(1) Work Summary

We applied this system to the installation of a partition wall in an office building, which is a reinforced concrete structure. An L-shaped drywall partition would be installed in a meeting room. The picture of the room before the installation and the top view of the partition wall are shown in Figure 7. The members of the wall were the runners, the studs, and the plasterboard.

\section{(2) Result of Test}

First, all of the members were precut based on the drawing. As shown in Figure 8, RFID tags were placed on the members, and their ID numbers were recorded in the database. Next, the members were installed in the order of runner, stud, and plasterboard. When an RFID tag was read as shown in Figure 9, the system recognized the member and sent the positioning data to the TS controller to indicate the positioning point with the laser. The operator installed the member according to this indication, as shown in Figure 10.

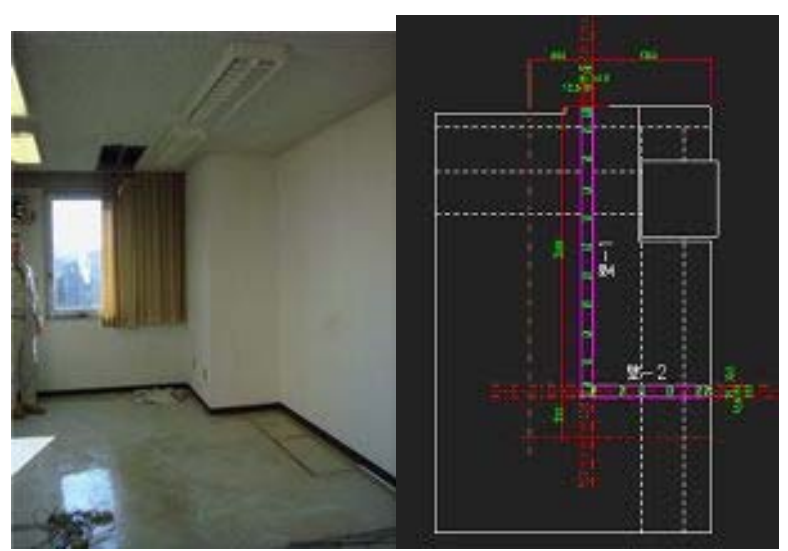

Fig.7. Intended Room and Partition Design

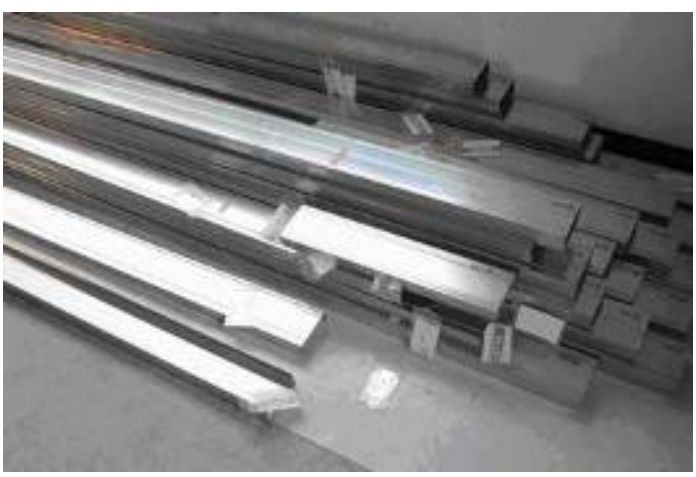

Fig.8. RFID Tags on Members

The partition wall was installed as shown in Figure11. It was impossible to indicate the positioning points of the runners, as shown in Figure 3(a), which would be installed under the beams because they were longer than the width of the beams, as shown in Figure12.

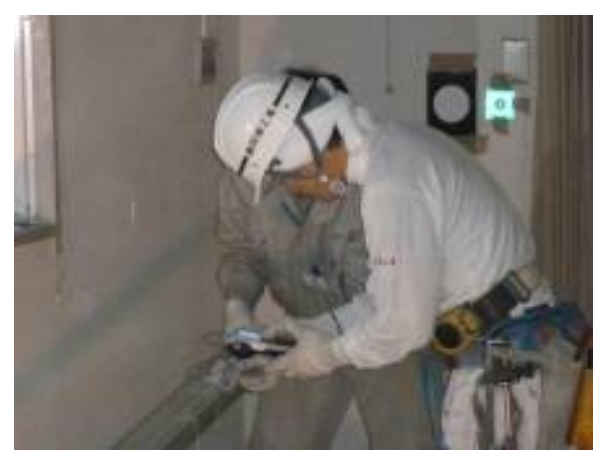

Fig.9. Reading RFID Tag with Handheld Reader 


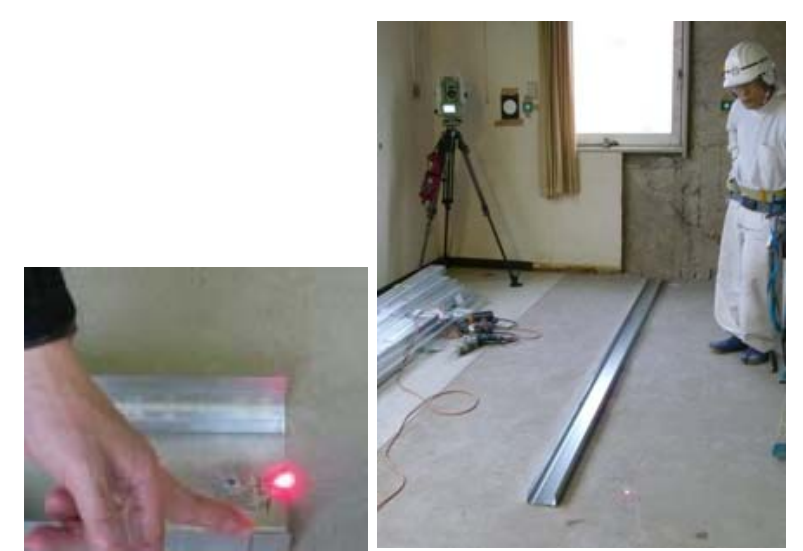

(a) Runner

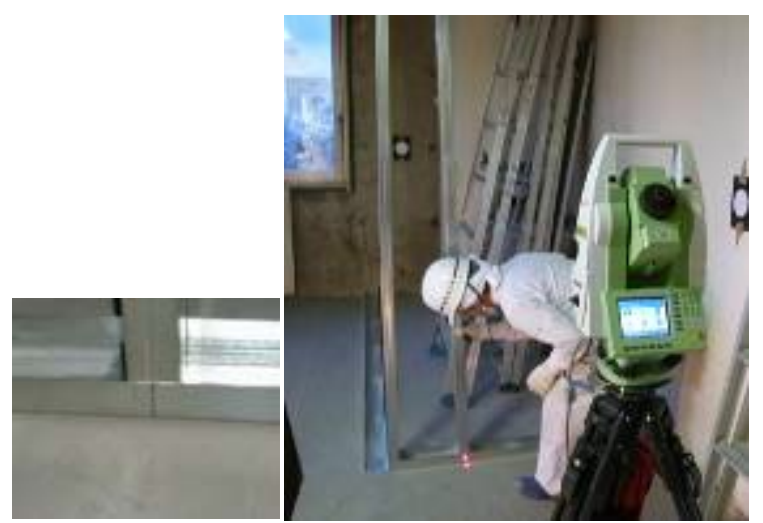

(b) Stud

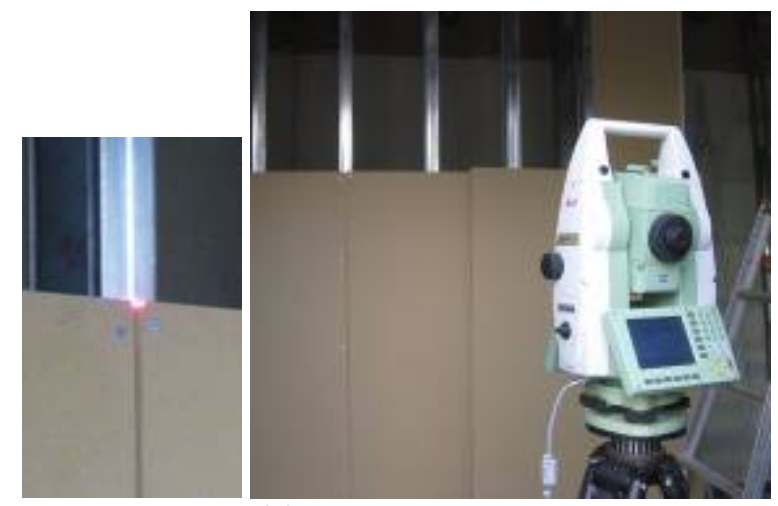

(c) Plaster Board

Fig.10. Laser Pointing
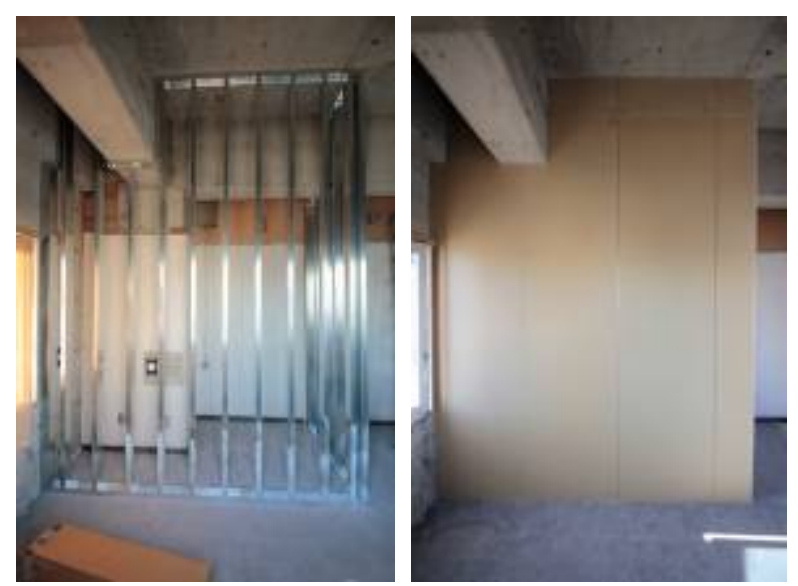

Fig.11. Result of Experiment

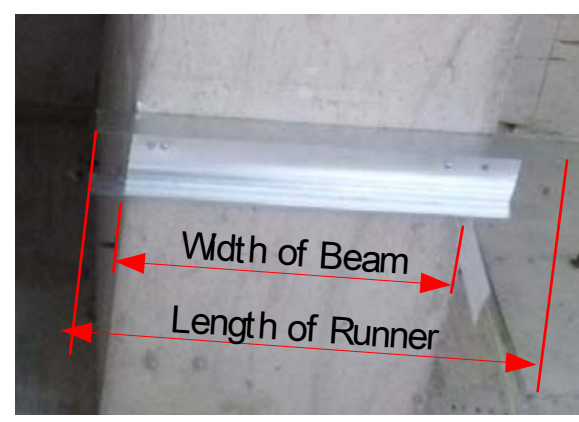

Fig.12. Runner Fixed under Beam

The positioning points for the runners should be defined with a consideration of the surface attached to the frame.

\section{Application to piping work in air-conditioning machine room}

(1) Work Summary

We applied this system to the renovation of the equipment in the air-conditioning machine room of the office building. The draft is shown in Figure 13. In this test, the system was applied only to the piping.

(2) Result of Test

As shown in Figure 14, the members were manufactured in a factory, and RFID tags were placed on

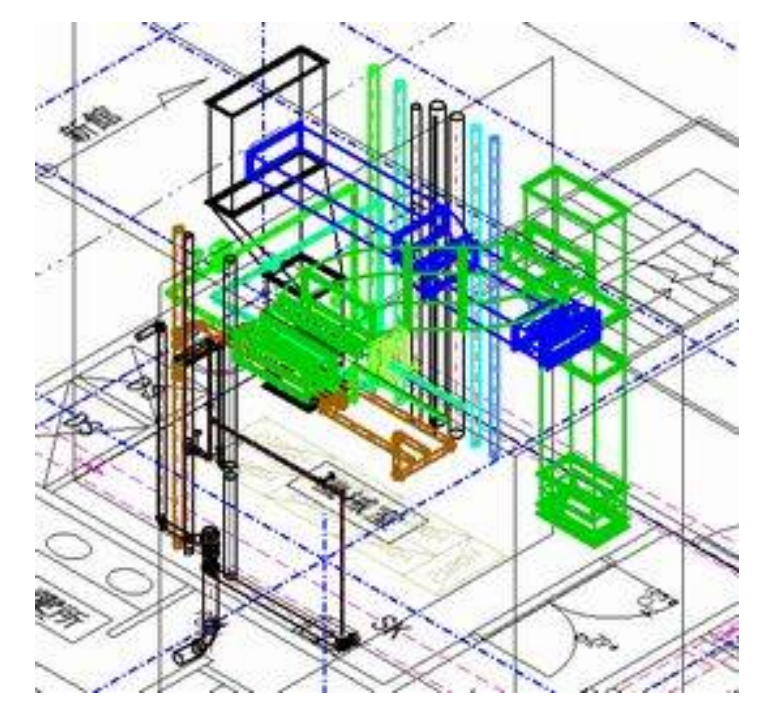

Fig.13. Draft of Pipes and Ducts 


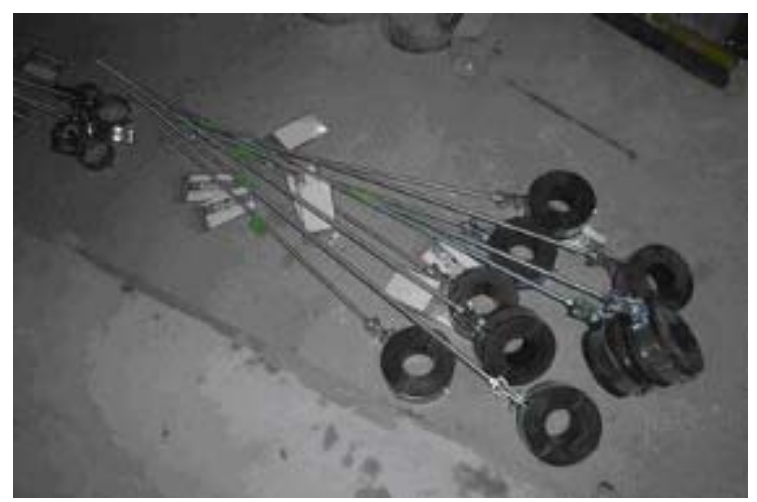

(a) Hanger

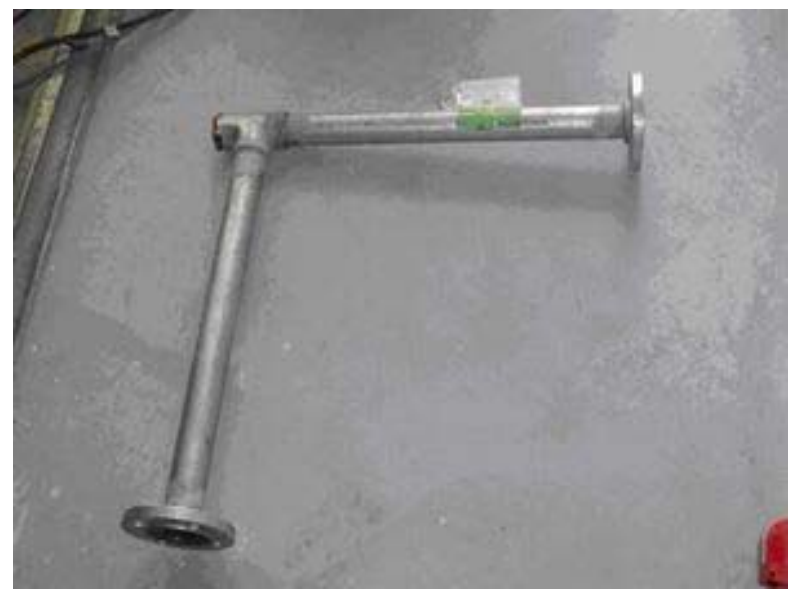

(b) Pipe

Fig.14. Members with RFID Tags

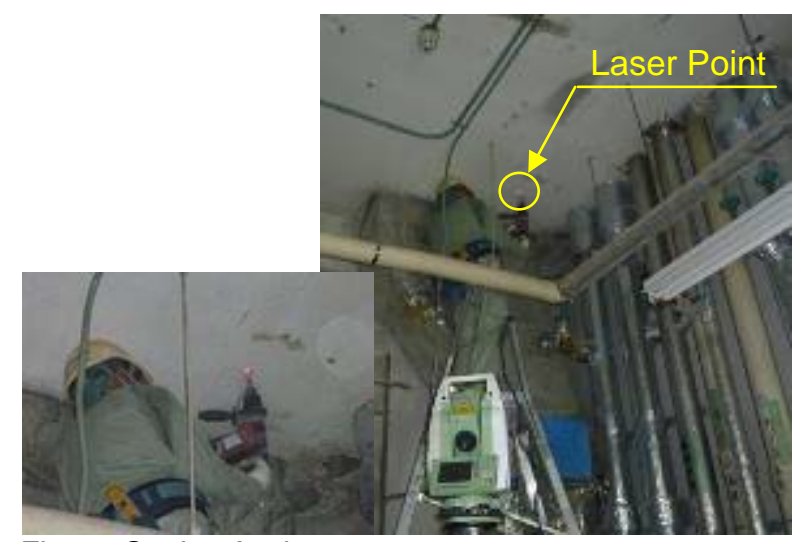

Fig.15. Setting Anchor

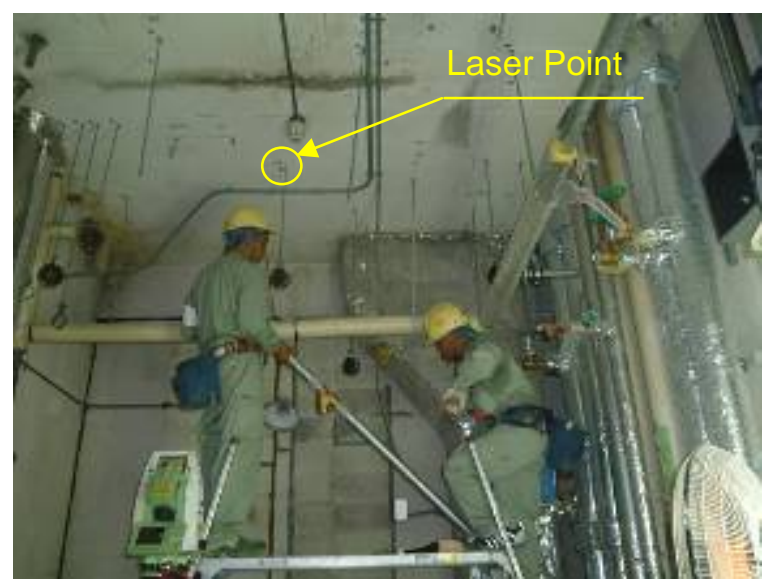

Fig.16. Setting Pipe

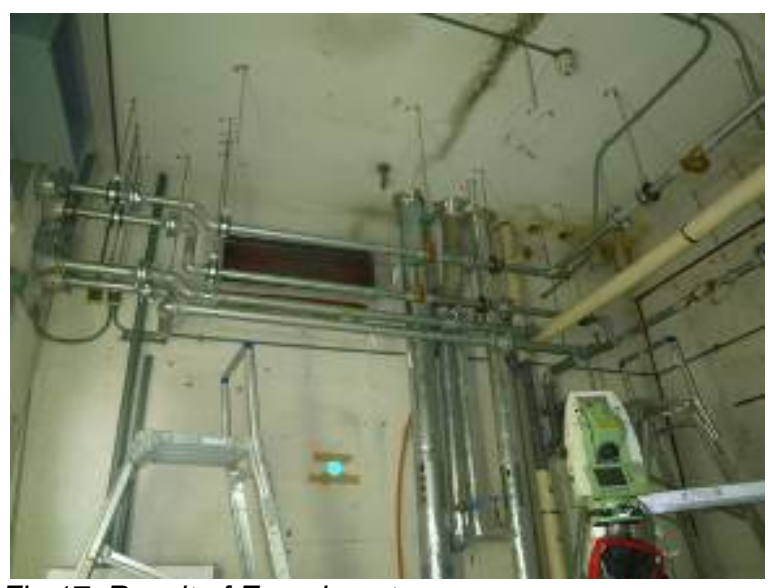

Fig.17. Result of Experiment

them. First, the tags on the support members (the hangers) were read, the anchors were set directly on the positions indicated by the laser of the total station as shown in Figure 15, and the hangers were set on them. Next, the tags on the pipes were read, the total station indicated the anchor positions of the hangers (as shown in Figure 16), and the operator set them according to the indication.

The pipework installed using this system is shown in Figure 17. All of the members could be set just as shown in the draft.

\section{Determining future research topics}

We initially considered that it might be possible to omit the marking process because the members are installed directly according to the laser indication. However, we found that it was necessary to mark the positioning points for the members with multiple points such as the runner of the partition wall because it is impossible to indicate multiple points simultaneously. We think that it is necessary to consider a different method for indicating points in order to omit the marking, for example, indicating multiple points quickly and repeatedly.

In addition, it is impossible to extract the member you want to install. Considering the fact that an installation generally has a specific order, we think that the proposed method of extracting the intended member and of packing and transporting the members is appropriate.

\section{Conclusion}

In this work, we described a method for positioning construction members accurately and reasonably by defining the positioning points for member objects and connecting the objects to the members using RFID tags in a positioning system with a total station. In addition, we demonstrated the effectiveness of this system and suggested future research topics for this system through two field tests. 


\section{References}

1. Hirokawa, T., et al., "Construction Management System for Banking Using Automatic Tracking Total Station", Proceeding of the 54th Annual Conference of Japan Society of Civil Engineering, Vol.54, pp. 40-41, 1999.

2. Ito, K., et al., "Consideration of Usability of a PC Card for Total Station Measurement for Development of a Construction information System Using an IC Card.", Proceeding of the 50th Annual Conference of Japan Society of Civil Engineering, Vol.50, pp. 370-371, 1995.
3. Sakamoto, S., et.al., "Laser Marking System Based on 3D CAD Model", ISARC2011, Vol. 1, pp. 58-63, 2011.

\section{Note}

This study was carried out as a subsidized project by The Ministry of Land, Infrastructure, Transport and Tourism. 